\title{
The impact of market factors on the development of eco-friendly energy technologies: the case of bioethanol
}

\author{
Humberto Merritt ${ }^{1}\left[\right.$ [ $\cdot$ Alejandro Barragán-Ocaña ${ }^{1}[\mathbb{C}$ \\ Received: 8 February 2021 / Accepted: 6 October 2021 / Published online: 30 October 2021 \\ (c) The Author(s), under exclusive licence to Springer-Verlag GmbH Germany, part of Springer Nature 2021
}

\begin{abstract}
Global warming is emerging as the most serious concern for the planet, with greenhouse gas emissions (GHG) contributing considerably to the problem. Consequently, warranting energy sustainability has turned into an urgent issue for scholars and policy-makers alike. Bioethanol has emerged as a viable eco-friendly replacement for avoiding GHG generating fossil fuels. However, bioethanol has faced several hurdles that have discouraged its development during these years. Apart from unpractical technological applications and failed ventures, bioethanol has been experiencing heavy competition from hydrocarbon fuels and adverse economic cycles. Currently, bioethanol is facing an uncertain scenario due to the combination of climbing crop prices and slow innovative production processes, including the cost-effective utilization of agriculture waste. Here, the impact of market conditions upon the competitive development of bioethanol is analyzed. It is argued that fluctuating fossil fuel prices over the last ten years has discouraged bioethanol's technological viability. As a result, the consolidation of industrial biotechnology, especially for biorefineries, has slowed down. Policy implications of recurrent fluctuations in the bioethanol market are also discussed.
\end{abstract}

Humberto Merritt

hmerritt@ipn.mx

Alejandro Barragán-Ocaña

abarragano@ipn.mx

1 Instituto Politécnico Nacional, CIECAS, Lauro Aguirre \#

120, Col. Agricultura, México, CDMX 11360, México 


\section{Graphic abstract}

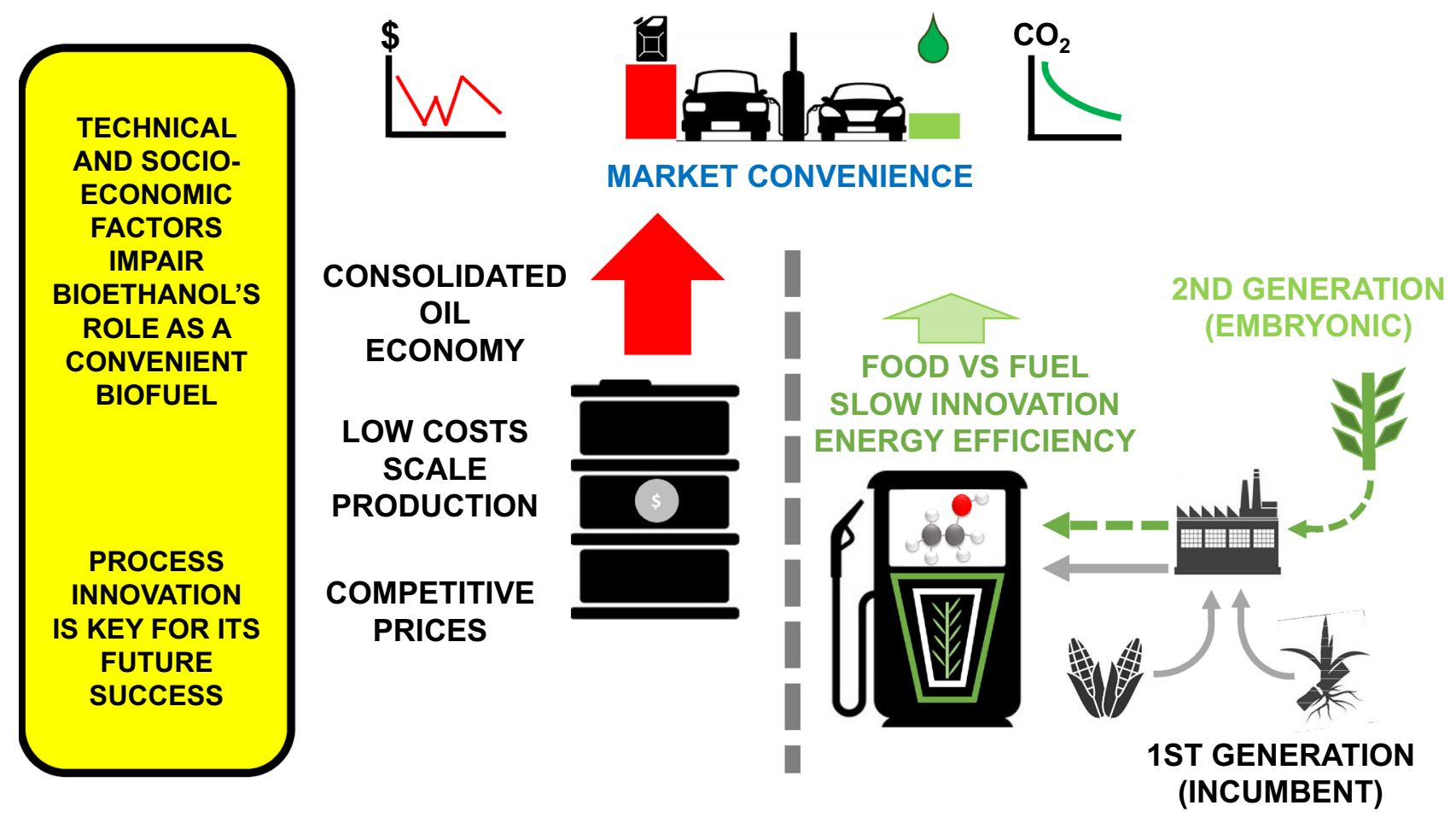

Keywords Bieconomy $\cdot$ Cleaner production $\cdot$ Bioethanol $\cdot$ Market conditions $\cdot$ Public policy

\section{Introduction}

Global warming has become increasingly relevant to world public opinion as the number of climate emergencies grows. According to the United Nations Office for Disaster Risk Reduction (UNDDR 2020), several catastrophic weather events have been primarily driven by rising global temperatures and other climatic alterations. Scientific evidence has associated global warming with higher carbon dioxide concentrations from greenhouse gas emissions (GHG), mainly produced by fossil fuel combustion (Beard et al. 2021).

Although almost all economic activities depend on fossil fuels, two decisive sectors, international aviation and maritime transport have remained relatively distant from stringent GHG regulations. Yet, the 2015 Paris climate agreement mostly centered on the scale and impact of their GHG emissions without attacking pollutant emissions from shipping or aviation. For instance, worldwide, flights produced 915 million tons of carbon dioxide in $2019 .{ }^{1}$ Therefore,

\footnotetext{
${ }^{1}$ See Air Transport Action Group. https://www.atag.org/facts-figur es.html. Accessed 5 July 2021.
}

reducing GHG emissions from fossil fuels is an urgent environmental goal, with cleaner energy alternatives such as bioethanol emerging as a viable technological solution. Still, bioethanol usage relies on public opinion to pressure governments in order to privilege renewable energy sources (Philp 2018).

However, bioethanol's commercial expansion confronts several difficulties. For example, the push for corn-based bioethanol has created much controversy among scholars, environmental organizations, and opinion leaders who argue that its promised technological and ecological benefits do not compensate for its actual socio-economic costs. Many critiques relate to the so-called food versus fuel debate (Hill et al. 2006). Another strand is the competitive fight between fossil fuels and bioethanol as a reliable alternative energy source (Rotman 2008). And there is also controversy about the effectiveness of newer technologies to process biomass feedstock efficiently (Persson et al. 2017). This paper reviews these criticisms by analyzing bioethanol's technological trajectory and market performance, including recent discussions regarding its impact on agriculture and organic waste treatment. It is argued that oscillating fossil fuel prices over the last fifteen years have discouraged bioethanol's 
techno-economic viability. The article is structured in five sections, including the introduction and conclusions. The following section discusses bioethanol production and its role as biofuel.

\section{The production and utilization of bioethanol as a biofuel}

Biofuels are convenient, eco-friendly energy alternatives as countries seek to reduce fossil fuels, cut carbon emissions and push farm revenues higher (Esmaeili et al. 2020). Bioethanol, an alcoholic biofuel used to power cars since the early twentieth century, is the fastest growing biofuel and currently constitutes about 10 percent of the fuel burned by motor vehicles (RFA 2020). According to the U.S. Energy Information Administration (EIA), transport bioethanol must be anhydrous, which is less than 1 percent water, and must be denatured to make it unfit for human consumption. ${ }^{2}$ Two different processes can produce it. First-generation bioethanol depends on starch or sugar to produce bioethanol. Still, this technology has raised multiple concerns related to the food versus fuel debate and the dilemma for environmental sustainability. The second-generation process harnesses (cellulosic) biomass feedstocks to make bioethanol. This technology process is especially suitable for agriculture waste such as corn stover and energy crops like switchgrass (Panicum virgatum L.) (Esmaeili et al. 2020). Because secondgeneration bioethanol comes from lignocellulosic material, edible crops can be destined for fuel production. However, second-generation bioethanol has not yet scaled up to an industrial level for technical and socio-economic reasons. Yet, further research is still needed to understand and abate the generation of vapor pollutants from bioethanol (when used as a biofuel), as the production of acetaldehydes, for example (Albernaz et al. 2019).

Although bioethanol has been praised as a convenient alternative to hydrocarbon fuels used by cars, the evidence is mixed. For example, Coelho and Goldemberg (2004) argue that bioethanol works as a superior motor fuel because of its lower evaporative emission. However, Nylund et al. (2008) point out that bioethanol used as a blending component in gasoline may lead to troubles with phase separation in cold conditions. Moreover, when used at high concentrations, e.g., E85, ethanol creates problems with corrosion, aldehyde emissions, and startability. In addition, bioethanol manufacturing inputs are also different. Lignocellulosic feedstock, such as corn stalks and stover, switchgrass, sugar bagasse, and rice straws, can be used to get the stuff. Recent studies

\footnotetext{
${ }^{2}$ U.S. Energy Information Administration. Ethanol. https://www.eia. gov/energyexplained/biofuels/ethanol.php. Accessed 5 July 2021.
}

suggest that switchgrass is a better alternative for corn than corn stover both economically and environmentally. The condition is that minimum monetary incentives should be used to switch from corn-based to corn-stover-based and switchgrass-based bioethanol supply chains (Esmaeili et al. 2020).

Nylund et al. (2008) provide some essential comparative facts between gasoline and bioethanol regarding basic fuel properties. At 15 Celsius, Gasoline's density is 0.75 , whereas that of bioethanol is 0.79 . The octane number (RON) for gasoline is 95-99, and for bioethanol is 108. The heat value $(\mathrm{MJ} / \mathrm{kg})$ for gasoline is 43 , and for bioethanol is 26.4. Bioethanol's tank size (to one of gasoline) is 1.8 , and bioethanol's performance measured by the equivalent distance driven of petrol is $70 \%$. In terms of production efficiency, Coelho and Goldemberg (2004) compare bioethanol's fossil fuel consumption (FFC) ${ }^{3}$ in Brazil (from sugarcane) with that of corn-based bioethanol from the United States. They found that Brazilian sugarcane bioethanol had an FFC of 1.89 mega-joules (MJ) by liter of bioethanol. In contrast, the lowest reported FFC from the U.S. corn-based bioethanol was 7.19 MJ/liter. They conclude that Brazilian sugarcane bioethanol is more energy-efficient.

However, the calculations of the environmental impacts associated with bioethanol's life cycle assessment (LCA) lack a consistent methodological approach, as Agostini et al. (2020) have pointed out. They argue that flaws in the interpretation phase of influential bioenergy LCA studies have fueled misleading policy conclusions.

Corn-based technology also conveys additional criticisms. For example, Hill et al. (2006) point out that the net energy balance (NEB) for corn grain bioethanol is small, providing roughly 25 percent more energy than required for its production. Higher energy input is then needed to produce corn and convert it into bioethanol. However, Lee et al. (2021) have recently reported that corn-based bioethanol biorefineries have introduced newer techniques to increase bioethanol yield, reduce energy use, and add extra by-products. They suggest that stemming from innovation in bioethanol technology may certainly help reduce the GHG emissions of corn bioethanol.

Yet, second-generation bioethanol technology is not fully competitive for technical and socio-economic reasons. Technological drawbacks emerge from hydrolyzing elements such as cellulose, lignin, and hemicellulose (Dias et al. 2011); with the production of cellulosic bioethanol that uses high-density, fast-growing woody crops (short rotation)

\footnotetext{
${ }^{3}$ Fossil fuel consumption in bioethanol production (FFC) corresponds to diesel oil use in the agricultural phase and during transport, to coal and natural gas use in corn-based ethanol plants, and to natural gas use for fertilizer production (Coelho and Goldenmberg 2004).
} 
in marginal lands within the central zone of Chile standing out as a promising alternative (Acuña et al. 2017). Other technological options for bioethanol production include waste bread (Han et al. 2017) and cotton liner and textile waste (Jeihanipour and Taherzadeh 2009).

Socio-economic obstacles stem from the manufacture of corn-based bioethanol because large amounts of the edible crop are diverted to produce it, prompting the outcry of public opinion (Banerjee 2011). These factors have turned the light on the unintended consequences of widespread bioethanol usage, such as the trade-off between devoting increasing land resources to bioethanol or committing them to feed people (Runge and Senauer 2007). This socio-economic dilemma militates against bioethanol's societal approval (Persson et al. 2017).

\section{Innovation and patenting activity in bioethanol technology}

Technical innovation is usually measured through patentbased statistics because they reflect the inventive performance of countries, firms, and other aspects of the dynamics of the innovation process. So, patent indicators help understand the innovation system, and those factors that support economic growth (Schmoch and Khan 2019).

In the case of bioethanol technology, the long-awaited second-generation (corn stover and switchgrass) bioethanol technology, usually considered as a plausible biological process for large-scale, cost-effective production of lignocellulosic bioethanol, has remained elusive because of ineffective plant scalability and feedstock fluctuations (Klein-Marcuschamer and Blanch 2015). Some of the main production drawbacks reported by the literature relate to the technical difficulty of treating complex lignocellulosic substrates, which require the prior degradation of their constituent polysaccharides, cellulose, and hemicellulose fractions, into their building blocks. As a result, pretreatment has been pointed out as the main bottleneck and one of the most expensive processing steps in cellulosic biomass-to-fermentable sugars conversion (Gírio et al. 2017).

In order to assess the development level of bioethanol technology, a search for patent documents in the Patenscope database (https://patentscope.wipo.int/search/en/search.jsf) was carried out to measure the rate of technological innovation in the production of all forms of bioethanol. The advanced search option was bioethanol AND production, which means that the search covered both first- and second-generation technologies. Results include the following options: (a) all offices; (b) English language; (c) automatic separation of words into lexemes; and (d) grouping by simple patent family. The search period covered from 1984 to 2020, and 5208 results were obtained. However, the research only analyzed the 2000-2020 period because of its relevance. Fig. A (in Supplimentary information) exhibits a rising trend in patent applications from 2006 to 2014 that decreased afterward. Although more detailed analysis is needed, reported figures still suggest that patenting activity in second-generation bioethanol technology has declined after peaking in 2014 . Then, achieving greater technical efficiency and lowering production costs remain the main obstacles for bioethanol to become an effective eco-friendly alternative to fossil fuels.

\section{The role of public policy in encouraging bioethanol}

The U.S. government spurred bioethanol production by introducing the Renewable Fuel Standard (RFS). The RFS was first created in the Energy Policy Act of 2005 and was later amended by the Energy Independence Act (EISA) of 2007. The RFS rule sought to reinforce environmental regulation by setting obligatory standards for blending bioethanol with gasoline (De Gorter and Just 2010).

As a result of the RFS rule, there was a notable rise in bioethanol-fueled vehicles. These automobiles operate in the United States under two types of commercial gasoline: (1) the E85 gas, which is a specification for gasoline-ethanol blends containing 51\% to $83 \%$ ethanol to ensure proper vehicle starting, operation, and safety in varying temperature conditions, and the E10 type, which is made up of 90 percent regular unleaded and 10 percent bioethanol (Nylund et al. 2008). Because the percentage of bioethanol depends on the geographical location of consumers and time of the year, American biofuel producers tend to add more bioethanol during the summer (Rotman 2008). On the environmental side, the RFS mandates production of 36 billion gallons of biofuels annually by 2022, of which 58 percent must come from advanced biofuels, such as cellulosic (secondgeneration) bioethanol, while only 15 billion gallons can be produced from food crops (first-generation) such as corn. At present, there are over 200 corn bioethanol plants in the U.S. that elaborate almost 15 billion gallons of corn-based bioethanol (Esmaeili et al. 2020).

According to Debnath et al. (2017), more bioethanol has to be used in high-blend fuels in order to achieve the proposed higher mandates of RFS. Yet, vehicles using E85 (i.e., flex-fuel cars) exhibit advantages and disadvantages. According to the webpage Car and Driver, the principal benefits of flex-fuel are (1) cleaner effects for the environment; (2) burning facility; (3) advanced technology; (4) sustainable production; (5) tax benefits; and (6) improved performance. The main drawbacks are (1) sole crop use, (2) 
Fig. 1 The monthly evolution of commodity crops and biofuels prices. 2005-2020. Notes: Gasoline: N.Y. Harbor Conventional Gasoline Regular Spot Price f.o.b. (Free on Board), US\$ per gallon. Bioethanol: US\$ per gallon. Daily price f.o.b. converted into monthly average price as reported by the USDA. Sugar: Sugar (world), International Sugar Agreement (ISA) daily price, raw, f.o.b. and stowed at greater Caribbean ports, US\$ per ton. Sources: Gasoline. https://www.index mundi.com/commodities/? commodity $=$ gasoline $\&$ months $=$ 360. Bioethanol: https://marke tnews.usda.gov/mnp/ls-reportconfig. Sugar: https://www. indexmundi.com/commodities/? commodity $=$ sugar $\&$ months $=$ 360

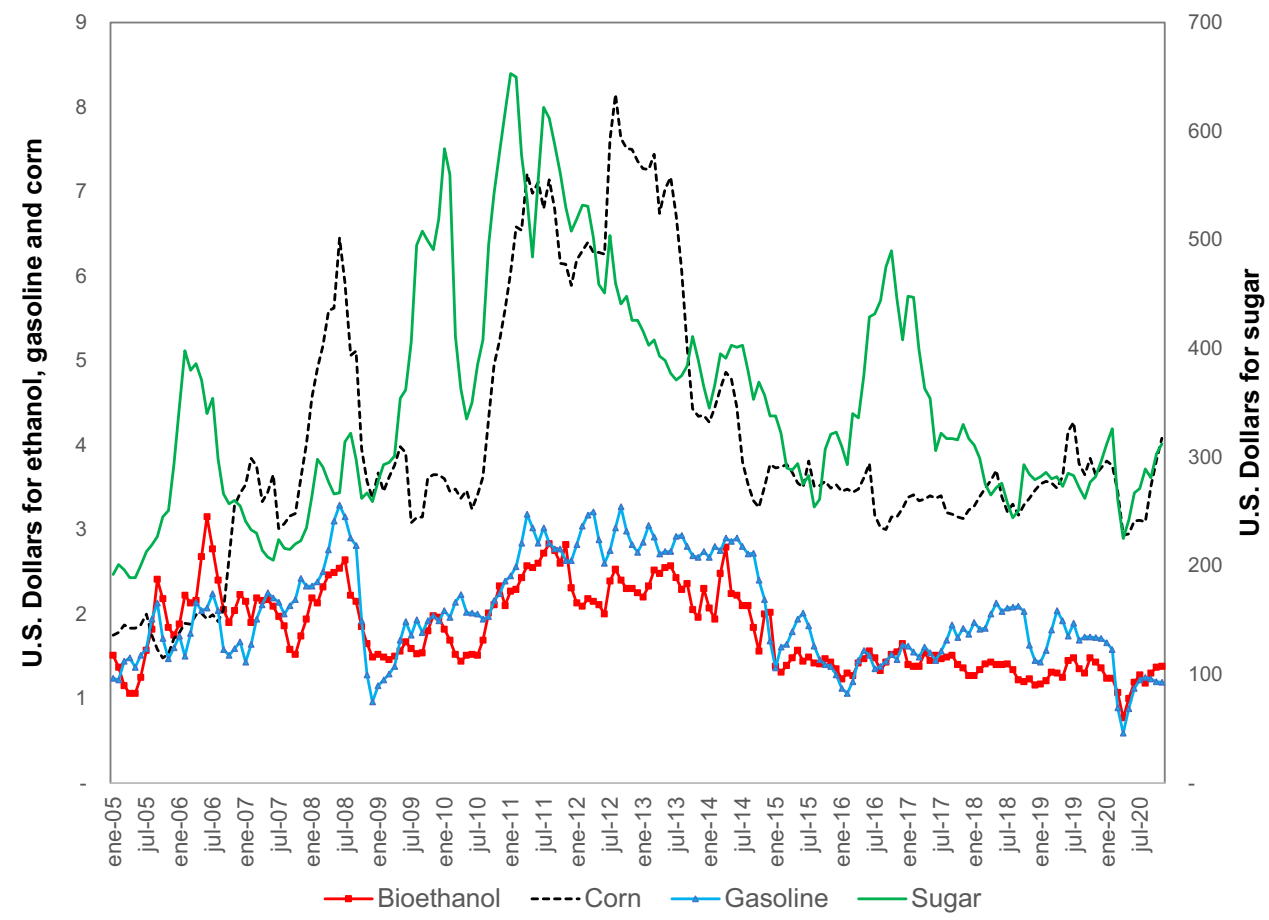

possible engine damage, (3) gas mileage, and (4) scarcity of fuel stations. ${ }^{4}$

Currently, bioethanol is the leading liquid biofuel, with a worldwide production of 29 billion gallons in 2019 (RFA 2020). The principal producers are the United States and Brazil, which account for 84 percent of the global production. And because American bioethanol is chiefly produced from corn (maize), rising oil prices inevitably push corn production up and thus endangering food consumption (Banerjee 2011).

\section{The economics of bioethanol in the U.S.}

The economics of bioethanol in the United States has been described by Parsons (2014). He highlights the following points: supply and demand are affected by shifts in the gasoline market, with the government setting the rules. American authorities have established a market situation that practically guaranteed economic viability. First, to create a market, the government passed laws mandating that retail gasoline must contain bioethanol, but oil firms would have little interest in blending bioethanol without the rule. Second, the government laws considered the impact of substitutes. Because Brazil is very efficient in producing sugar-based bioethanol, it could potentially export bioethanol to America at prices

\footnotetext{
${ }^{4}$ See https://www.caranddriver.com/research/a31542970/flex-fuelbenefits/. Accessed 2 July 2021.
}

lower than those manufactured in America. So, import barriers were established to prevent the importation of low-cost Brazilian bioethanol. Third, domestic bioethanol production was initially uneconomical, requiring a significant investment in infrastructure. Thanks to its vast political power, the U.S. government was capable of undercutting production costs and thus encouraging the construction of biorefineries to supply the domestic market (Parsons 2014). But these actions were of limited effect given the recurrent instability of global oil markets between 2005 and 2015, as Fig. 1 shows.

The drama for the bioethanol market is that of the wellknown boom-and-bust cycle of commodities: when prices are high, production is driven up, and then the market becomes oversupplied, causing prices to crash. The worrying effect is that large-scale corn production to make bioethanol pressures crop markets forcing bioethanol to cut margins to compete due to rising costs and uncertain input availability (Morgan 2021). To describe the effects of market conditions on bioethanol, monthly prices (from January 2005 to November 2020) for sugar and corn, together with bioethanol and gasoline, are displayed next.

Gasoline prices exhibit a diminishing trend after 2011, with a quasi-identical movement for bioethanol because both markets are closely related. So, bioethanol immediately becomes cheaper when gasoline drops and vice versa. Consequently, declining oil prices tend to foster GHG emissions (Carpio 2019). The close link between gasoline and bioethanol can be verified through a Pearson correlation coefficient test, as Table 2 shows. 
Table 1 Pearson correlation coefficients for gasoline, bioethanol, corn, and sugar. 2005-2020. Sources: Authors' elaboration

\begin{tabular}{llll}
\hline Correlations & Ethanol & Corn & Sugar \\
\hline Gasoline & $0.776^{* *}$ & $0.745^{* *}$ & $0.476^{* *}$ \\
Ethanol & - & $0.583^{* *}$ & $0.469^{* *}$ \\
Corn & - & - & $0.580^{* *}$ \\
\hline
\end{tabular}

**Correlation is statistically significant at the 0.01 level (2-tailed)
Measuring the relationship between bioethanol and gasoline: empirical results

The research seeks to test the market relationship between bioethanol and gasoline by posing the following hypothesis: fluctuations in the price of petrol determine that of bioethanol, but not the other way around. To test the relationship, a Granger causality test (GCT) was performed to check for

Fig. 2 Trend analysis for the U.S. bioethanol market. 2005-2020. Notes: US\$ per gallon. Daily price f.o.b. converted into monthly average price as reported by the USDA. Source: Iowa State University. Agricultural Marketing Resource Center (Ag MRC). https://www. agmrc.org/. Accessed 25 January 2021

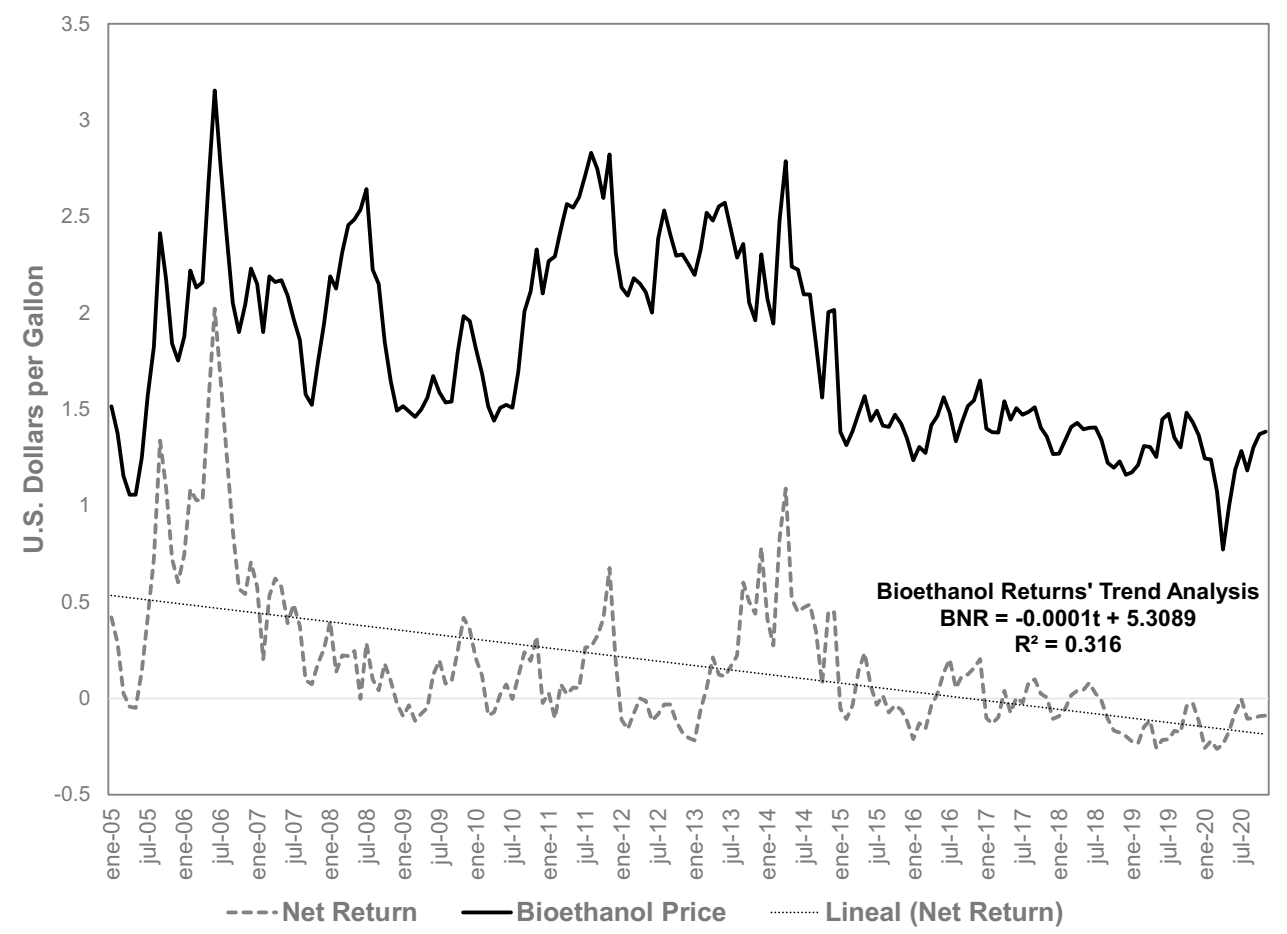

Table 1 correlation test hints at an apparent relationship between bioethanol's market fluctuations and profits. That is, profits for U.S. corn-based biorefineries may depend on feedstock prices, which in turn depend on crop availability. Bioethanol tends to encounter waving profits as price variations may come from variations on the feedstock or changes in the fuel markets responding to consumer behavior. In this respect, statistical data and analyses from the Iowa State University's Agricultural Marketing Resource Center confirm that bioethanol profitability has been systematically diminishing since 2005 at a rate of 0.01 U.S. cents per month, even having negative returns since July 2018 , as a result of commodity market conditions. To assess these patterns, Fig. 2 displays the time series of bioethanol price and its respective net return, reporting also the corresponding regression analysis. Historical figures suggest that bioethanol profits (i.e., net return) for U.S. biorefineries are not necessarily linked to higher prices in the fuel market, as the left side of the graph shows for 2005-2007. A more detailed analysis of these trends is carried out next. the direction and statistical significance between prices for gasoline and bioethanol.

\section{Data}

The analysis was carried out using monthly data for bioethanol and gasoline for the period 2005-2020. The data concerning gasoline were obtained from the U.S. Energy Information Administration's statistical information through the Index Mundi online database. ${ }^{5}$ Bioethanol prices were collected from the U.S. Department of Agriculture's marketing service. ${ }^{6}$ The time series are in U.S. dollars per gallon, expressed in current prices.

\footnotetext{
5 Data retrieved https://www.indexmundi.com/commodities/?commo dity $=$ gasoline $\&$ months $=360$. Accessed 25 January 2021 .

${ }^{6}$ Data retrieved from https://marketnews.usda.gov/mnp/ls-reportconfig. Accessed 25 January 2021.
} 


\section{Method}

A Granger causality test (GCT) was conducted to test the potential relationship between gasoline and bioethanol.

GCT is a statistical approach for determining whether one time series is a factor and offers reliable forecasting information. To be operative, Granger (1988) states that GCT considers only discrete time series with a time lag of one. In addition, there is no reason for the available data to be measured on the same unit of time that the definitions would require for a proper test of causation.

It is worth noting, however, that GCT has the following shortcomings: (1) estimates can be either severely biased or of high variance, both leading to spurious results; (2) even if estimated correctly, causality estimates alone are not interpretable without examining the component behaviors of the system model; and (3) GCT ignores critical components of a system's dynamics (Agung 2009).

It has been assumed that empirical results derived from GCT may help test the causal link between bioethanol and gasoline, and they can probably be indicative but not conclusive of the relationship (if any). Yet, the relationship dynamics between both variables should be taken into consideration for further study.

In addition, GCT can also help validate whether price fluctuations are not random because a commercial link has existed during the 15 years under analysis. Empirical data comprehended monthly statistics, which fulfills Granger's considerations. Moreover, if the probability value is less than the minimum acceptable level, then the hypothesis would be rejected at that level (Granger 1988). Table 2 reports the basic statistics.

Figures in Table 2 show that both series exhibit relatively close values, although the mean price for bioethanol is lower than gasoline. Besides, both series are not normally distributed, as the Jarque-Bera test demonstrates.

\section{Empirical Results}

Empirical results from the statistical analysis of the time series from bioethanol and gasoline for the 2005-2020 period are reported in Table 3.

When four lags are applied (as a reasonable delay), the hypothesis that gasoline does not involve Granger causality of bioethanol can be rejected at the $1 \%$ level of significance, whereas the idea that bioethanol does not involve Granger causality of gasoline cannot be dismissed at the 5\% level of significance. As a complementary step of the Granger causality test, stationarity tests must be performed for each relevant variable. In this study, the augmented Dickey-Fuller (ADF) test procedure was employed for implementing stationarity tests. The ADF statistic suggests that the examined
Table 2 Descriptive statistics for gasoline and ethanol time series. 2005-2020

\begin{tabular}{lll}
\hline Variable & Ethanol & Gasoline \\
\hline Mean & 1.802 & 2.022 \\
Median & 1.65 & 1.94 \\
Maximum & 3.15 & 3.29 \\
Minimum & 0.77 & 0.59 \\
Std. Dev & 0.4824 & 0.6010 \\
Skewness & 0.4053 & 0.2870 \\
Kurtosis & 2.1344 & 2.1357 \\
Jarque-Bera & 11.1906 & 8.5672 \\
Probability & 0.0037 & 0.0138 \\
Sum & 344.23 & 386.24 \\
Sum Sq. Dev & 44.21 & 68.63 \\
Observations & 191 & 191 \\
\hline
\end{tabular}

Pearson correlation: 0.7759 (Prob. 0.0001)

Table 3 Pairwise granger causality tests. Sources: Authors' elaboration

\begin{tabular}{lll}
\hline Null Hypothesis: & F-Statistic & Prob \\
\hline $\begin{array}{l}\text { GASOLINE does not Granger } \\
\text { Cause ETHANOL }\end{array}$ & 4.04191 & 0.0037 \\
$\begin{array}{l}\text { ETHANOL does not Granger } \\
\text { Cause GASOLINE }\end{array}$ & 1.84791 & 0.1217 \\
\hline
\end{tabular}

Sample: 2005M01-2020M11. Lags: 4. Valid observations: 187

variables have a unit root, which means they are non-stationary (Agung 2009).

\section{Discussion}

The GCT results exhibit a unidirectional causality running from gasoline to bioethanol, but they do not prove an inverted causality running from bioethanol to gasoline. Empirical evidence suggests that bioethanol is heavily affected by the oil market. Its expansion is therefore dependent on the price base that gasoline could have. Thus, the price of gasoline determines the price of bioethanol, but not the other way around. These results confirm that bioethanol is not yet a viable market substitute for gasoline. Yet, bioethanol prices can still be affected by fluctuations in the sugarcane market, as Lima et al. (2019) have pointed out. However, more statistical tests are needed to check for the long-run relationship between both commodities.

On the other hand, policy implications rely on the possible generalization of these findings to different contexts, such as developing countries. Nonetheless, being the United States a large and open economy, this evidence remains significant. Even though a further examination of current market data, especially after the 2020 world health crisis, is 
highly recommended, this analysis is, unfortunately, out of the scope of this paper.

\section{Conclusions}

This research analyzed why bioethanol has not yet taken off as an ecological energy source. Empirical evidence suggests that the confluence of several factors has hindered bioethanol. Firstly, there is a negative effect produced by frequent price fluctuations in energy markets, making bioethanol unprofitable when gasoline prices drop. When gasoline is more expensive, demand for bioethanol rises as consumers seek cheaper substitutes. However, increasing demand also raises production costs because higher bioethanol production drives up the costs of edible crops. Therefore, as the price of corn rises, bioethanol producers would eventually need to seek other feedstock alternatives. This effect could be corrected if second-generation technology was competitive enough, a scenario that has yet to appear.

Secondly, the research suggests that fluctuations in the price of gasoline determine the cost of bioethanol, but not conversely. This result indicates that bioethanol is not yet a feasible substitute for gasoline. The United States government tried to moderate these effects by introducing the RFS regulation in 2005, which sought to create a sufficiently large consumer base to make bioethanol production profitable. However, after the continuous fall in the oil price since 2011, bioethanol's competitiveness discouraged innovation efforts to materialize bioethanol production from lignocellulose. Thirdly, world energy markets currently face greater uncertainty due to the recent COVID-19 pandemic, which has put significant pressure on world finances and global commodity markets. All of which impinge upon the long-term search for better bioethanol technology.

There are several implications of this study. First, socioeconomic factors can hinder the expansion of environmentally friendly technologies if they are neglected. Second, policy-makers should pay more attention to market forces in order to encourage viable eco-friendly energy alternatives for fossil fuels. Third, developing countries can take advantage of their natural resource allocation when pushing for efficient energy sources if substitution effects are positive. Yet, some caveats are worth mentioning. First, the research has only considered the impact of the prices of fossil fuels and agricultural inputs on the performance of the bioethanol market. Second, it fails to delve into the institutional effects of the U.S. policies that sought to push bioethanol, albeit this issue could be a constructive topic for future works. Finally, empirical results indicate that advances in technological knowledge should help bioethanol become competitive in its own right.
Supplementary Information The online version contains supplementary material available at https://doi.org/10.1007/s10098-021-02225-6.

\section{References}

Acuña E, Cancino J, Rubilar R, Parra C (2017) Bioethanol potential from high density short rotation woody crops on marginal lands in Central Chile. Cerne 23(1):133-145. https://doi.org/10.1590/ 01047760201723012278

Agostini A, Giuntoli J, Marelli L, Amaducci S (2020) Flaws in the interpretation phase of bioenergy LCA fuel the debate and mislead policy-makers. Int J Life Cycle Ass 25(1):17-35. https://doi.org/ 10.1007/s11367-019-01654-2

Agung IGN (2009) Time series data analysis using EViews. John Wiley $\&$ Sons, Singapore

Albernaz AF, Correa E, Da Silva WB, Euclides HO, Barreto PRP (2019) Kinetics and mechanism of the $\mathrm{CH}_{3} \mathrm{CH}_{2} \mathrm{OH}$ with $\mathrm{H}_{2} \mathrm{O}$ reaction. Chem Phys Lett 734:136699. https://doi.org/10.1016/j. cplett.2019.136699

Banerjee A (2011) Food, Feed, Fuel: Transforming the Competition for Grains. Dev Chg. doi: https://doi.org/10.1111/j.1467-7660. 2011.01704.x

Beard S, Holt L, Tzachor A, Kemp L et al (2021) Assessing climate change's contribution to global catastrophic risk. Futures 127:102673. https://doi.org/10.1016/j.futures.2020.102673

Carpio LGT (2019) The effects of oil price volatility on ethanol, gasoline, and sugar price forecasts. Energy 181:1012-1022. https:// doi.org/10.1016/j.energy.2019.05.067

Coelho ST, Goldemberg J (2004) Alternative transportation fuels: contemporary case studies. In: Cleveland CJ (ed) Encyclopedia of energy. Elsevier, Amsterdam, pp 67-80

De Gorter H, Just DR (2010) The social costs and benefits of biofuels. App Ec Pers Pol 32:4-32. https://doi.org/10.1093/aepp/ppp010

Debnath D, Whistance J, Thompson W, Binfield J (2017) Complement or substitute: Ethanol's uncertain relationship with gasoline under alternative petroleum price and policy scenarios. App Enr 191:385-397. https://doi.org/10.1016/j.apenergy.2017.01.028

Dias MOS, Cunha MP, Jesus CDF, Rocha GJM, Pradella JGC et al (2011) Second generation ethanol in Brazil: can it compete with electricity production? Biores Technol 102(19):8964-8971. https://doi.org/10.1016/j.biortech.2011.06.098

Esmaeili SAH, Sobhani A, Szmerekovsky J et al (2020) First-generation vs. second-generation: a market incentives analysis for bioethanol supply chains with carbon policies. App Enr 277:1-19. https://doi.org/10.1016/j.apenergy.2020.115606

Gírio F, Marques S, Pinto F, Oliveira AC et al (2017) Biorefineries in the World. In: Rabaçal M, Ferreira AF, Silva CAM, Costa M (eds) Biorefineries: Targeting Energy, High Value Products and Waste Valorisation. Springer, Cham, pp 227-281. https://doi.org/ 10.1007/978-3-319-48288-0_9

Granger CWJ (1988) Some recent development in a concept of causality. Jou Econmtrcs 39(1):199-211. https://doi.org/10.1016/03044076(88)90045-0

Han W, Hu Y, Li S, Huang J, Nie Q et al (2017) Simultaneous dark fermentative hydrogen and ethanol production from waste bread in a mixed packed tank reactor. J Clean Prod 141:608-611. https:// doi.org/10.1016/j.jclepro.2016.09.143

Hill J, Nelson E, Tilman D, Polasky S et al (2006) Environmental, economic, and energetic costs and benefits of biodiesel and ethanol biofuels. Proc Nat Ac Sci USA 110(30):11206-11210. https://doi. org/10.1073/pnas.0604600103

Jeihanipour A, Taherzadeh MJ (2009) Ethanol production from cottonbased waste textiles. Bioresource Technol 100(2):1007-1010. https://doi.org/10.1016/j.biortech.2008.07.020 
Klein-Marcuschamer D, Blanch HW (2015) Renewable fuels from biomass: technical hurdles and economic assessment of biological routes. AIChE Jou 61(9):2689-27011. https://doi.org/10.1002/ aic. 14755

Lee U, Kwon H, Wu M, Wang M (2021) Retrospective Analysis of the U.S. Corn Ethanol Industry for 2005-2019: Implications for Greenhouse Gas Emission Reductions. Biofpr, In Press. doi: https://doi.org/10.1002/bbb.2225

Lima CRA, De Melo GR, Stosic B, Stosic T (2019) Cross-Correlations between Brazilian Biofuel and food market: Ethanol versus sugar. Physica A. https://doi.org/10.1016/j.physa.2018.08.080

Morgan T (2021) Ethanol Plant Ceases Production. AgWeb Farm Jou. 5/01/2021. https://bit.ly/3yTLXAu

Nylund N-O, Aakko-Saksa P, Sipilä K (2008) Status and Outlook for Biofuels, Other Alternative Fuels and New Vehicles (Research Note No. 9789513869892). VTT, Helsinki. https://bit.ly/3tdyn9U

Parsons B (2014) Economics of ethanol and biodiesel. In: Dahiya A (ed) Bioenergy. Academic Press, Amsterdam, pp 523-539

Persson M, Erdei B, Galbe M, Wallberg O (2017) Techno-economic aspects in the evaluation of biorefineries for production of secondgeneration bioethanol. In: Ruiz HA, Thomsen MH, Trajano HL (eds) Hydrothermal processing in biorefineries: production of bioethanol and high added-value compounds of second and third generation biomass. Springer, Cham, pp 401-420. https://doi.org/ 10.1007/978-3-319-56457-9_17
Philp J (2018) The bioeconomy: the challenge of the century for policy makers. New Biotech 40:11-19. https://doi.org/10.1016/j.nbt. 2017.04.004

RFA (2020) Ethanol industry outlook. Renewable fuels association, Washington. https://bit.ly/3h7xICi

Rotman D (2008) The Price of Biofuels Tech Rev 111:42-51

Runge CF, Senauer B (2007) How Biofuels could starve the poor. Forgn Aff 86:41-53

Schmoch U, Khan M (2019) Methodological challenges for creating accurate patent indicators. In: Glänzel W, Moed HF, Schmoch U, Thelwall M (eds) Handbook of science and technology indicators. Springer, Cham, pp 907-927. https://doi.org/10.1007/978-3-03002511-3_37

United Nations Office for Disaster Risk Reduction (UNDDR) The Human Cost of Disasters: An Overview of Last 20 Years (20002019). https://bit.ly/3DLoRzE

Publisher's Note Springer Nature remains neutral with regard to jurisdictional claims in published maps and institutional affiliations. 